International Journal of Engineering \& Technology, 7 (3.27) (2018) $456-465$
International Journal of Engineering \& Technology
WPC
Website: www.sciencepubco.com/index.php/IJET
Research paper

\title{
Aerodynamic Analysis on Wind Turbine Aerofoil
}

\author{
Albi $^{1^{*}}$, M. Dev Anand ${ }^{2}$, G.M. Joselin Herbert ${ }^{3}$ \\ ${ }^{1}$ PG Student, Department of Mechanical Engineering, Noorul Islam Centre for Higher Education, Kumaracoil, Tamil Nadu, India. \\ ${ }^{2}$ Professor and Director Research, Department of Mechanical Engineering, Noorul Islam Centre for Higher Education, Kumaracoil, \\ Tamil Nadu, India. \\ ${ }^{3}$ Professor, Department of Mechanical Engineering, Noorul Islam Centre for Higher Education, Kumaracoil, Tamil Nadu, India. \\ *Corresponding author E-mail:albinkhan@gmail.com
}

\begin{abstract}
The aerofoils of wind turbine blades have crucial influence on aerodynamic efficiency of wind turbine. There are numerous amounts of research being performed on aerofoils of wind turbines. Initially, I have done a brief literature survey on wind turbine aerofoil. This project involves the selection of a suitable aerofoil section for the proposed wind turbine blade. A comprehensive study of the aerofoil behaviour is implemented using 2D modelling. NACA 4412 aerofoil profile is considered for analysis of wind turbine blade. Geometry of this aerofoil is created using GAMBIT and CFD analysis is carried out using ANSYS FLUENT. Lift and Drag forces along with the angle of attack are the important parameters in a wind turbine system. These parameters decide the efficiency of the wind turbine. The lift force and drag force acting on aerofoil were determined with various angles of attacks ranging from $0^{\circ}$ to $12^{\circ}$ and wind speeds. The coefficient of lift and drag values are calculated for $1 \times 10^{5}$ Reynolds number. The pressure distributions as well as coefficient of lift to coefficient of drag ratio of this aerofoil were visualized. The CFD simulation results show close agreement with those of the experiments, thus suggesting a reliable alternative to experimental method in determining drag and lift.
\end{abstract}

\section{Introduction}

Concerns about global climate change and its impact and, at the same time, the continuous depletion of fossil fuel reserves have significantly increased demand for alternative energies. The research into clean and renewable energy resources, such as solar energy and wind power energy, is a key subject of alternative energy development. Wind energy is one of the most promising alternative energy sources because of its relatively lower cost and pollution. Power has been extracted from the wind over hundreds of years with historic designs, known as windmills, constructed from wood, cloth and stone for the purpose of pumping water or grinding corn. Historic designs, typically large, heavy and inefficient, were replaced in the 19th century by fossil fuel engines and the implementation of a nationally distributed power network. A greater understanding of aerodynamics and advances in materials, particularly polymers, has led to the return of wind energy extraction in the latter half of the 20th century. Wind power devices are now used to produce electricity, and commonly termed as wind turbines. Figure 1.1 and 1.2 shows the growth rate of wind generator capacities. The total installed capacity of wind power generators was $159,079 \mathrm{MW}$ at the end of 2009 which has increased significantly in the last few years to $369,597 \mathrm{MW}$ at the end of 2014 (GWEC report 2014).

Among the countries that utilize wind energy for extensive power productions, USA and China took the lead. China installed 23,196 MW of wind power capacity in 2014 alone and took over the global number one position from USA. The USA and China accounted for about $48.8 \%$ of the world wind turbine installation. India holds to rank five with a total installed capacity of 22,465 MW. India installed 2,315 MW of wind power in the year 2014 (GWEC report 2014).
Based on the experience and growth rates of the past years, WWEA expects that wind energy will continue its dynamic development also in the coming years. Although the short term impacts of the current finance crisis makes short-term predictions rather difficult, it can be expected that in the mid-term wind energy will rather attract more investors due to its low risk character and the need for clean and reliable energy sources. More and more governments understand the manifold benefits of wind energy and are setting up favorable policies, including those that are stimulation decentralized investment by independent power producers, small and medium sized enterprises and community based projects, all of which will be main drivers for a more sustainable energy system also in the future. Carefully calculating and taking into account some insecurity factors, wind energy will be able to contribute in the year 2020 at least $12 \%$ of global electricity consumption. By the year 2020, at least $1500000 \mathrm{MW}$ can be expected to be installed globally. A recently published study by the Energy Watch Group (EWG) reveals, as one out of four described scenarios, that by the year 2025 it is even likely to have $7500000 \mathrm{MW}$ installed worldwide producing $16400 \mathrm{TWh}$ All renewable energies together would exceed $50 \%$ of the global electricity supply. As a result, wind energy, along with solar, would conquer a 50\% market share of new power plant installations worldwide by 2019. Globally non-renewable power generation would peak in 2018 and could be phased out completely by 2037 . The creation of the International Renewable Energy Agency (IREA), which was founded in January 2009, will act as a catalyst and further speed up the deployment rates of renewable energies: directly through providing know-how to its currently 76 member countries and through acting as a balancing lobby at international decision making processes such as the UN climate change negotiations. 


\section{Literature Review}

Writing audit is one of the degree considers. It fills in as manual for run this examination. It will give part so as to get the data about breeze turbine sharp edge examination utilizing CFD. From the beginning time of the task, different writing examines have been finished. Research diaries, books, printed or online meeting article were the fundamental source in the task guides.

Abdullateef A. Jadallaha et al., [1] has give that the major point in wind turbine performance is Blade Element Method and Momentum theory Which gives some important parameter like tip speed Ratio, Pitch angle, Number of blade and wind speed. For low power wind turbine above parameter acts as a basis fundamental on blade design. The Optimization of wind turbine performance calculation based on Low wind speed to high wind speed by the changing of Pitch angle, angle of attack and tip speed Ratio.

Carrigan et al., [2] effectively exhibited a completely mechanized process for advancing the aerofoil cross-area of a VAWT. The age of NACA aerofoil geometries, half and half work age, and flimsy CFD were combined with the DE calculation subject to tip speed proportion, robustness, and cutting edge profile plan requirements. The streamlining framework was then used to acquire an advanced sharp edge cross-area for 2 test cases, bringing about plans that accomplished higher effectiveness than the benchmark geometry. The advanced outline for the first experiment accomplished proficiency is $2.4 \%$ higher than the benchmark geometry. The expansion in proficiency of the streamlined geometry was credited to the disposal of a main edge partition bubble that was causing a lessening in productivity and an increment in cyclic stacking. For the second experiment, the VAWT was given finished geometric adaptability as both the edge shape and rotor strength was permitted to change amid the streamlining procedure. This brought about a geometry that accomplished productivity $6 \%$ higher than the pattern NACA 0015 geometry. This expansion in productivity was a consequence of the $40 \%$ lessening in robustness combined with the 58\% expansion in thickness, prompting a slight stage move in the torque and higher general pinnacle execution.

Abdulkadir Ali et al., [3] studied the VAWT configuration for two different set of blades (steel made and cardboard made) using partially and fully cowled configuration this analysis resulted in high rotational motion for the partially cowled configuration of the of cardboard made turbine this also resulted in heavier the turbine higher the wind speed will required to generate the rotational motion, the lighter turbine resulted a better performance at all the speeds.

W. T. Chang et al., [4] introduced a innovative devise called as Omni-Directional -Guide-Vane (ODGV) integrated with VAWT ODGV effectively improved the self-starting behavior of the VAWT. At $6 \mathrm{~m} / \mathrm{s}$, the rotor rotational speed was increased by $125 \%$ at free-running condition and the power output at maximum torque was 3.48 times higher for the ODGV integrated VAWT compared to the bare VAWT.

Huimin Wang et al., [5] this paper introduced the numerical reenactment of Vertical Axis Wind Turbine with Reynolds Average Navier-Stokes conditions and Realizable $\mathrm{k}-\varepsilon$ turbulence show at various breeze speed. It utilized FLUENT programming for performed CFD investigation. They utilize NACA 0018 aerofoil arrangement for made the sharp edge 2D display where the measurements of edges are: Chord length of the cutting edge = 0.1 , Diameter of rotor $=0.9 \mathrm{~m}$, Rotational speed $=100 \mathrm{rpm}$ and furthermore made the $\mathrm{C}-\mathrm{H}$ compose space for $\mathrm{CFD}$ investigation whose measurement are: $\mathrm{C}$ is a half crescent shape whose span = $16 \mathrm{~m}, \mathrm{H}$ is a square shape whose size are $=32 \mathrm{~m} * 30 \mathrm{~m}$.

Results demonstrates wind speeds builds swirl existed in downstream locale, add up to torque coefficients tend to smooth, speed conveyance at upstream is huge.
Ji Yao et al., [6] considered

A two dimensional model of three cutting edge $\mathrm{H}$ compose vertical pivot wind turbine was built up in this paper, at that point the two dimensional shaky stream field of the vertical hub wind turbine was reproduced numerically for Standard $\mathrm{k}-\varepsilon$ turbulence models and RNG $\mathrm{k}$

$-\varepsilon$

turbulence models. The outcomes demonstrated that the impact of various turbulence models on the speed field is less, on the weight field is moderately extensive, and on the estimation of the aggregate torque is significantly bigger. The inclination of the speed and weight around the breeze turbines cutting edge was evident. The speed field

\section{Seung Yong Min et al., [7] examined an exploration}

for the execution change of the straight-bladed vertical pivot wind turbine streamlined investigation; control instrument plan and its acknowledgment of $1 \mathrm{kw}$ class show are done. 4 straight sharp edges of $1 \mathrm{~m}$ traverse length are utilized and rotor range is settled to $1 \mathrm{~m}$. The

streamlined examination demonstrates that the cycloid breeze turbine is conceivable to produce more power than settled pitch compose VAWT by changing its pitch edge and stage edge as indicated by wind course and wind speed.

By boosting the distracting power in each pivoting sharp edge at the particular turning position, ideal pitch edge variety is acquired. Also, a few aerofoil states of NACA 4-digit and NACA 6arrangement are contemplated. Streamlined investigation indicates execution change of $60 \%$

Farooq Ahmad Najar et al., [8] have investigated wind turbine blade geometric design and optimization, aerodynamics analysis, wind turbine blade structural design and dynamics analysis. Blade geometric design addresses the design parameters, including aerofoils and their aerodynamic coefficients, attack angles, design tip speed ratio, design and/or rated wind speed, rotor diameter, blade aerodynamic shape with chord length and twist distributions, so that the blade achieves an optimum power performance. The geometry of the blade is S809 an aerodynamic shape can be obtained based on the BEM theory with respect to given aerofoil with known aerodynamic coefficients. Computational fluid dynamics (CFD) model has been used to calculate the aerodynamic effect on the blade aerofoil. Critical Reynolds number and constant wind speed has been considered during analysis under different turbulence models via, spallartalmaras, k-epsilon, flow. During investigation it is observed that only k-epsilon showed efficient results than others and 14 degree angle of attack (AOA) is the optimum value at which there is much lift coefficient and minimum drag.

Chris Kaminsky et al., [9] have been carried out the research of a VAWT using the NAC A0012-34 aerofoil. The system was modeled in Solid Works. They are use of the STAR CCM software to CFD analyzes the air flow around a vertical axis wind turbine to perform. Analysis has been done in three ways as show:

- To determine CFD analysis analyzed the 2D flow over the chosen aerofoil.

- Determine the analysis looked at the flow over a 3D representation of the aerofoil.

- Finally, a full VAWT assembly was created and analyzed at various wind directions at the same wind speeds.

The aerofoil then the 2D and 3D simulations used different angles of attack ( 0 to 15 degrees) and speeds $(15 \& 30 \mathrm{mph})$ to 
determine. The full assembly included 3 aerofoils that were attached into a $5 \mathrm{ft}$ high, $3 \mathrm{ft}$ diameter structure. The results of this research on the NACA 001234 aerofoil showed it could be a very viable choice for a residential VAWT. The $2 \mathrm{D}$ analysis gave a stall angle of about 8 degrees, however, the 3D analysis, it being more accurate, did not provide us with a stall angle. The results for the 3D full assembly analysis of vertical axis wind turbine were incomplete.

Jon DeCoste et al., [10] have objective of this project was to design and build a self-starting vertical axis wind turbine. This report outlines the first term efforts in the design of our full-scale VAWT. The self-starting issues surrounding VAWT will be tackled by the use of alternative blade profiles and pitching mechanisms As a result, three blade profiles will be tested and compared. Results from prototype testing in the wind tunnel will reveal the blade profile that offers the best performance for selfstarting.

As the blade rotates in a VAWT, the direction and magnitude of the effective wind velocity change in a cyclic manner. Figure 4.2 shows a simple schematic of the single aerofoil pitching motion which is similar to the VAWT blade. Thus, the oscillatory motion (pitching oscillation) of the blade can be assumed as; $\alpha=\alpha$ mean $+\alpha$ amp $\sin (\omega \mathrm{t})$

Where,

$\alpha$-mean $=$ mean angle of attack

$\alpha$-amp $=$ pitch oscillation amplitude $\omega=$ angular velocity.

$$
k=\text { reduced frequency, } \frac{w c}{2 u_{\omega}}
$$

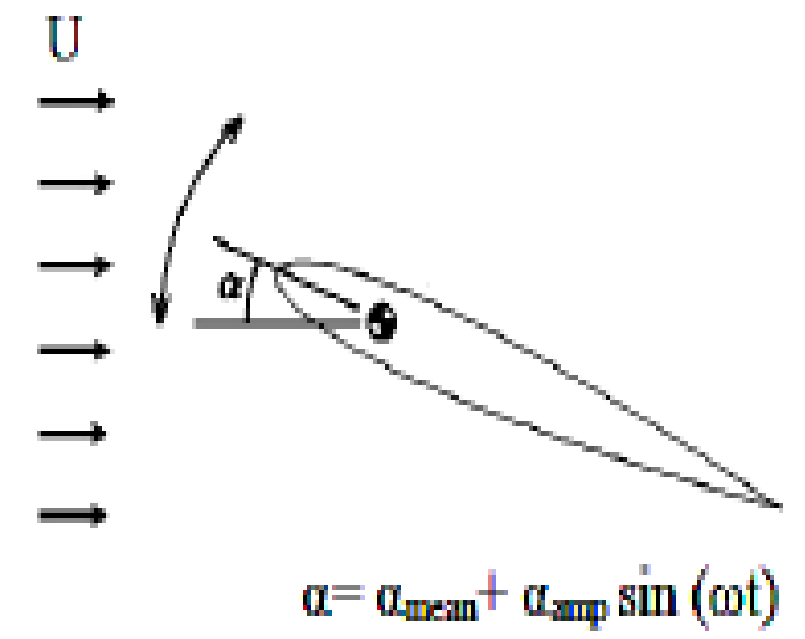

Figure 1: Simple schematic of the aerofoil pitching motion

\section{Computational Modeling}

The larger part of wind turbine explore is centered around precisely foreseeing effectiveness. Different computational models exist, each with their own qualities and shortcomings that endeavor to precisely foresee the execution of a breeze turbine. Portrayals of the general arrangement of conditions that the strategies illuminate can be found in next part. Having the capacity to numerically foresee wind turbine execution offers an enormous advantage over exemplary test systems, the significant advantage being that computational investigations are more practical than expensive analyses.

While different methodologies have been distributed, the three noteworthy models incorporate force models, vortex models, and computational liquid elements (CFD) models. Every one of the three models depend on the straightforward thought of having the capacity to decide the relative speed and, thus, the digressive power segment of the individual cutting edges at different azimuthal areas.

\section{Computational liquid dynamics}

Due to its adaptability, CFD has been picking up prevalence for breaking down the perplexing; temperamental optimal design associated with the investigation of wind turbines and has exhibited a capacity to create comes about that contrast positively and test information. Not at all like different models, CFD has demonstrated no issues anticipating the execution of either high-or low strength wind turbines or for different tip speed proportions. In any case, it is vital to take note of that anticipating the execution of a breeze turbine utilizing CFD regularly requires extensive computational areas with sliding interfaces and extra turbulence displaying to catch insecure effects; in this way, CFD can be computationally costly.

Framework age After the geometry for the VAWT had been characterized, the following stage is to discretize the computational area as a preprocessing venture in the

CFD process. The demonstration of discretizing the area is named framework age and is a standout amongst the most vital strides in the CFD procedure. For basic geometries where the heading of the stream is known in advance, making the framework is typically direct. For streams, for example, this, superb organized frameworks can be utilized that can precisely catch the stream material science. Be that as it may, as geometry ends up complex and the streams more hard to anticipate with the beginning of turbulence and partition, lattice age is never again a trifling errand. 


\section{Control Equation}

As the wind turbines Mach number at work is typically less than 0.3 , so the flow around the aerofoil could be considered as incompressible flow, the two dimensional incompressible N-S equations and two dimensional continuity equation are used as the control equations. The two dimensional incompressible N-S equation is expressed in vector as follows:

$\rho \frac{D V}{D t}=\rho f-\nabla p+\mu \nabla^{2} V$

Where $\mathbf{V}$ is the velocity vector, $\mathbf{f}$ is the volume force vector, $\mu$ is the dynamic viscosity.

The continuity equation is showed as follows:

$\nabla \cdot V=0$

Compared with the conventional k- $\varepsilon$ turbulence model, the content on rotation and curvature is added to the Realizable k- $\varepsilon$ model for the calculation of turbulence dynamic viscosity, and the equation of the dissipation rate $\varepsilon$ is amended. Therefore, the model been shown that could simulate the flow around a blunt body effectively. Reynolds averaged equations and continuity equations are showed as follows:

$\frac{\partial \overrightarrow{u_{l}}}{\partial t}+\overrightarrow{u_{l}} \frac{\partial \overrightarrow{u_{l}}}{\partial x_{i}}=-\frac{\partial \vec{p}}{\partial x_{i}}+\frac{\partial}{\partial x_{j}}\left[v \frac{\partial \overrightarrow{u_{l}}}{\partial x_{j}}-\rho \overrightarrow{u_{\imath} u_{j}}\right]$

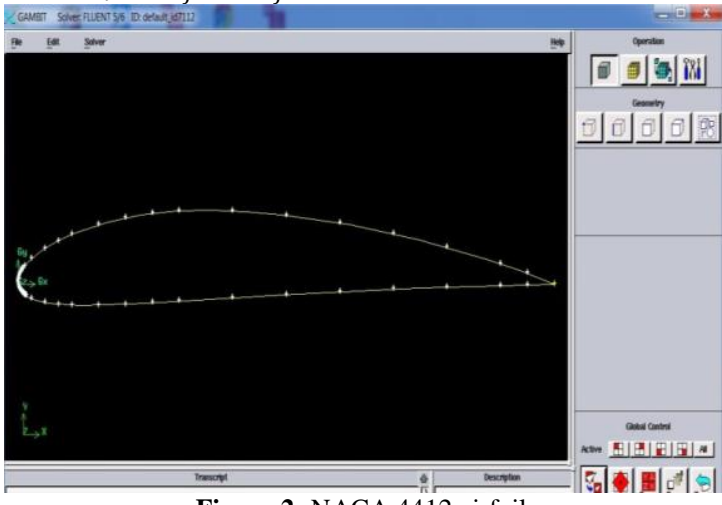

Figure 2: NACA 4412 airfoil $\frac{\partial \overrightarrow{u_{\imath}}}{\partial x_{i}}=0$

The mode equations of the turbulent kinetic energy $\mathrm{k}$ and turbulent kinetic energy dissipation rate $\varepsilon$ are:

$\frac{\partial k}{\partial t}+\overrightarrow{u_{\imath}} \frac{\partial k}{\partial x_{j}}=\frac{\partial}{\partial x_{i}}\left[\left(v+\frac{v_{t}}{\sigma_{t}}\right) \frac{\partial k}{\partial x_{j}}\right]+\left(\frac{\partial \overrightarrow{u_{\imath}}}{\partial x_{j}}+\frac{\partial \overrightarrow{u_{j}}}{\partial x_{j}}\right) \frac{\partial u_{i}}{\partial x_{j}}-\varepsilon$ $\frac{\partial(\rho \varepsilon)}{\partial t}+\frac{\partial\left(\rho \overrightarrow{u_{l}} \varepsilon\right)}{\partial x_{i}}=\frac{\partial}{\partial x_{i}}\left[\left(v+\frac{v_{t}}{\sigma_{\varepsilon}}\right) \frac{\partial \varepsilon}{\partial x_{j}}\right]+C_{1} \rho s \varepsilon-$ $C_{2} \rho \frac{\varepsilon^{2}}{k+\sqrt{v \varepsilon}}$

Realizable $\mathrm{k}-\varepsilon$ model has been widely used in various types of flow simulation, which includes Rotational average shear flow, free flow including jet and mixed flow, flow in pipes, boundary layer flow and backward-facing step flow, the result is consistent with the experimental data.

\section{CFD Analysis on NACA 4412 Aerofoil}

\section{Modelling}

The aerofoil NACA 4412 is chosen for blade modeling and study is shown in Figure 2. NACA 4420 profiles are obtained from Design Foil Workshop for various chords. The modeling is done with GAMBIT software. Figure 3 shows the meshing drawing of the aerofoil below.

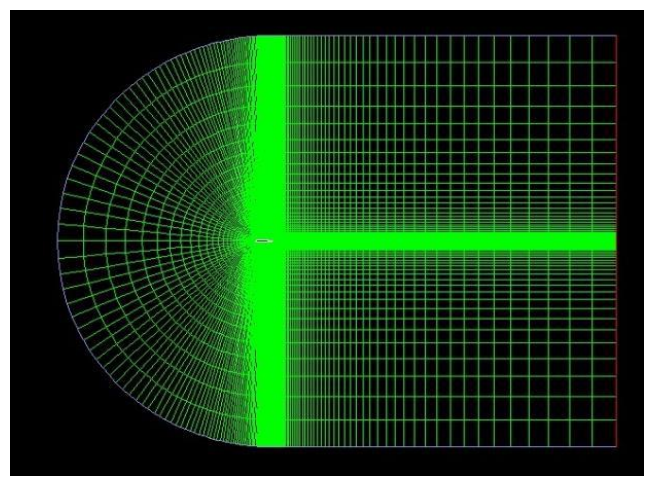

Figure 3: Completed mesh

Table 1: The Blade is Modeled for the Specification Given

\begin{tabular}{|l|l|}
\hline PROFILE & NACA 4412 \\
\hline Root Chord Length & $1651 \mathrm{~mm}$ \\
\hline Tip Chord Length & $650 \mathrm{~mm}$ \\
\hline Length of Blade & $10700 \mathrm{~mm}$ \\
\hline Hub Diameter & $337.5 \mathrm{~mm}$ \\
\hline Hub Length & $1465 \mathrm{~mm}$ \\
\hline Hub to Blade (neck) & $1475 \mathrm{~mm}$ \\
\hline
\end{tabular}

Table 2: FLUENT It sEt Little Parameters

\begin{tabular}{|l|l|}
\hline Solver & Pressure Based Steady State \\
\hline Viscous Model & Spalart-Allmaras \\
\hline Density $\left(\mathrm{kg} / \mathrm{m}^{3}\right)$ & 1.225 \\
\hline Viscosity $(\mathrm{kg} / \mathrm{m}-\mathrm{s})$ & 1.7894 \\
\hline Turbulent Viscosity Ratio & 10 \\
\hline Inlet Velocity & $18 \mathrm{~m} / \mathrm{s}$ \\
\hline Chord-Length & $0.1651 \mathrm{~m}$ \\
\hline Momentum & Second Order Upwind \\
\hline Pressure Velocity Coupling & Simple \\
\hline
\end{tabular}

\section{Lift and drag}

The velocity triangle of airfoil profile is used to calculate lift and drag forces shown in Figure 4. 


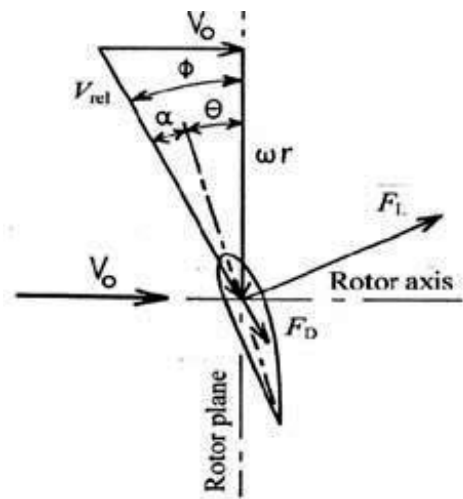

Figure 4: The velocity triangle of airfoil profile is used to calculate lift and drag forces

The value of $\varphi$ is found by the following formula. The wind velocity is taken as $8 \mathrm{~m} / \mathrm{s}$ and the speed is taken as $45 \mathrm{rpm}$.

$\varphi=\tan -1[8 /(2 \pi \mathrm{r}[45 / 60])]$

The angle of attack (AOA) $\alpha$ is found by the following formula; $\alpha=\varphi-\theta$

The angle of attack value is given as input in the Design Foil Workshop software and the values of CL and CD are found out.

The lift and drag forces are calculated by the following formula and the lift to drag ratio (L/D ratio) is also found out.

Lift $=(1 / 2) * \rho * C L * c * L * \operatorname{Vrel}^{2}$

Drag $=(1 / 2) * \rho^{*} \mathrm{CD}^{*} \mathrm{c} * \mathrm{~L} * \operatorname{Vrel}^{2}$

Where

- $\rho$ - density of air $-1.225 \mathrm{~kg} / \mathrm{m}^{3}$
- $\quad c-$ Chord length in meter $-1 \mathrm{~m}$

- $\quad \mathrm{L}$ - Length of the blade element - $1 \mathrm{~m}$

- Vrel - relative velocity of air in $\mathrm{m} / \mathrm{s}$

The values of $\mathrm{CL}$ and $\mathrm{CD}$ were found out for various angles of attack.[28]

Lift $=\left(0.5^{*} \rho^{*} \mathrm{c}^{*} \mathrm{~L} * \mathrm{CL} * \mathrm{Vrel}^{2}\right)$

Drag $=\left(0.5 * \rho * c^{*} L^{*} \mathrm{CD}^{*} \operatorname{Vrrel}^{2}\right)$

The Lift and Drag forces are calculated for the angle of attack from $0^{\circ}$ to $12^{\circ}$. The Lift/Drag ratio is calculated for different angle of attack ranges from $0^{\circ}$ to $20^{\circ}$ for the velocity ranges from 5 to $20 \mathrm{~m} / \mathrm{sec}$ as shown in Table 3 .

Table 3: Lift/Drag Ratio for Different Angle of Attack Ranges from $0^{\circ}$ to $20^{\circ}$

\begin{tabular}{|c|c|c|c|c|c|c|c|}
\hline \multirow{2}{*}{ AOA $(\alpha)$} & \multicolumn{9}{|c|}{ L/D RATIO } & \multicolumn{5}{c|}{} \\
\cline { 2 - 8 } & $\mathrm{V}_{\mathrm{O}}=5 \mathrm{~m} / \mathrm{s}$ & $\mathrm{V}_{\mathrm{O}}=7 \mathrm{~m} / \mathrm{s}$ & $\mathrm{V}_{\mathrm{O}}=10 \mathrm{~m} / \mathrm{s}$ & $\mathrm{V}_{\mathrm{O}}=12 \mathrm{~m} / \mathrm{s}$ & $\mathrm{V}_{\mathrm{O}}=15 \mathrm{~m} / \mathrm{s}$ & $\mathrm{V}_{\mathrm{O}}=17 \mathrm{~m} / \mathrm{s}$ & $\mathrm{V}_{\mathrm{O}}=20 \mathrm{~m} / \mathrm{s}$ \\
\hline 0 & 50.7 & 53.6 & 55.6 & 56.2 & 57.9 & 59.1 & 60.3 \\
\hline 1 & 59.7 & 62.4 & 64.7 & 68.5 & 69.9 & 71.3 & 72.8 \\
\hline 2 & 67.2 & 70.8 & 73.5 & 73.0 & 75.8 & 78.0 & 80.4 \\
\hline 3 & 70.0 & 73.0 & 76.3 & 80.6 & 82.2 & 83.2 & 85.3 \\
\hline 4 & 72.3 & 75.5 & 78.4 & 82.6 & 84.9 & 83.5 & 86.5 \\
\hline 5 & 74.3 & 77.8 & 81.1 & 83.6 & 85.0 & 84.7 & 88.0 \\
\hline 6 & 75.4 & 78.7 & 80.2 & 83.9 & 86.3 & 86.7 & 88.1 \\
\hline 7 & 69.2 & 72.5 & 75.1 & 79.7 & 81.5 & 88.0 & 85.0 \\
\hline 8 & 65.8 & 68.7 & 71.4 & 75.5 & 77.1 & 78.8 & 80.1 \\
\hline 9 & 64.4 & 64.5 & 66.8 & 70.7 & 72.1 & 74.0 & 75.1 \\
\hline 10 & 59.6 & 62.2 & 61.6 & 65.2 & 66.7 & 68.0 & 69.3 \\
\hline 11 & 54.6 & 56.7 & 58.8 & 61.9 & 63.4 & 64.8 & 63.6 \\
\hline 12 & 49.7 & 51.6 & 53.3 & 56.2 & 57.5 & 58.7 & 59.7 \\
\hline
\end{tabular}

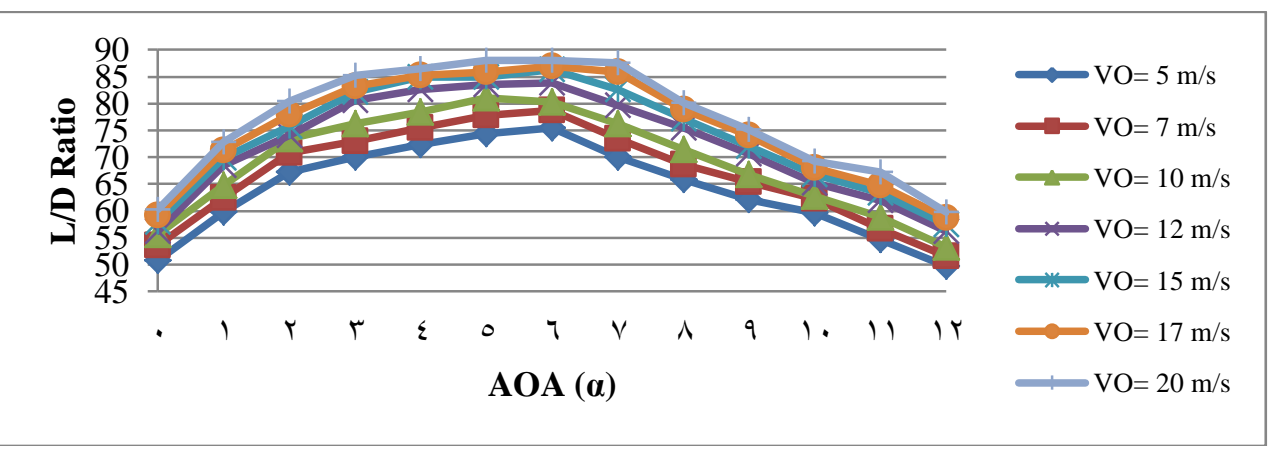

Figure 5: Angle of attack 


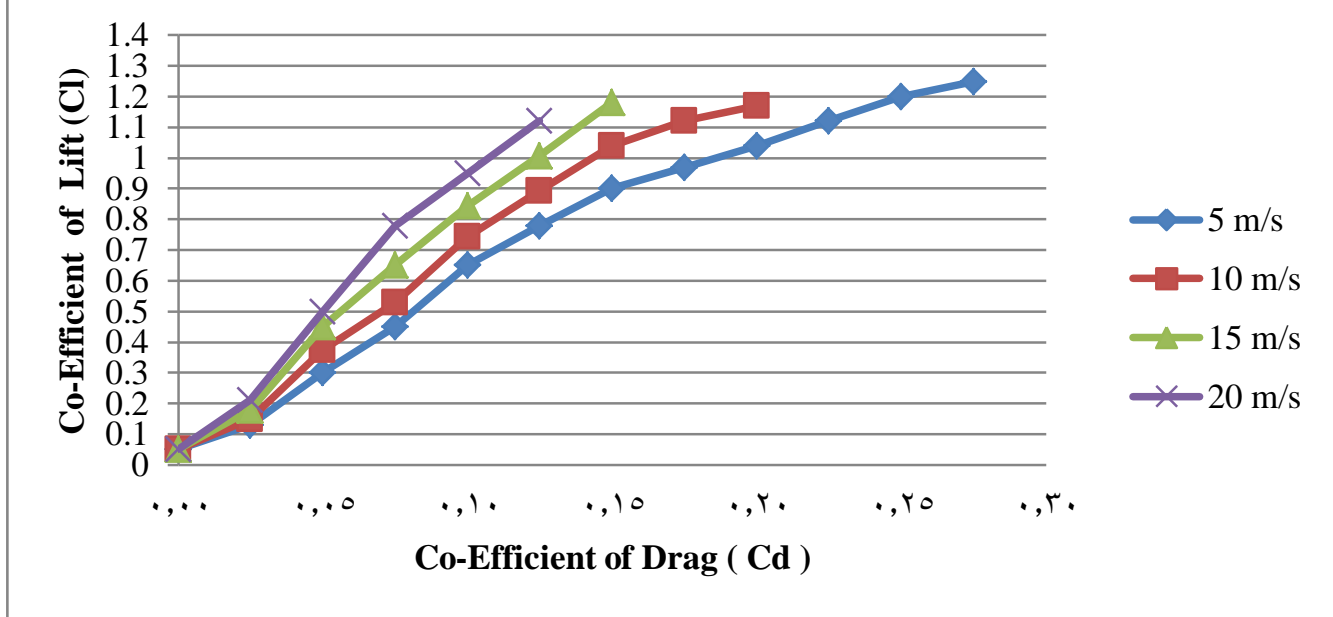

Figure 6: Correlation between $C_{1}$ and $C_{d}$

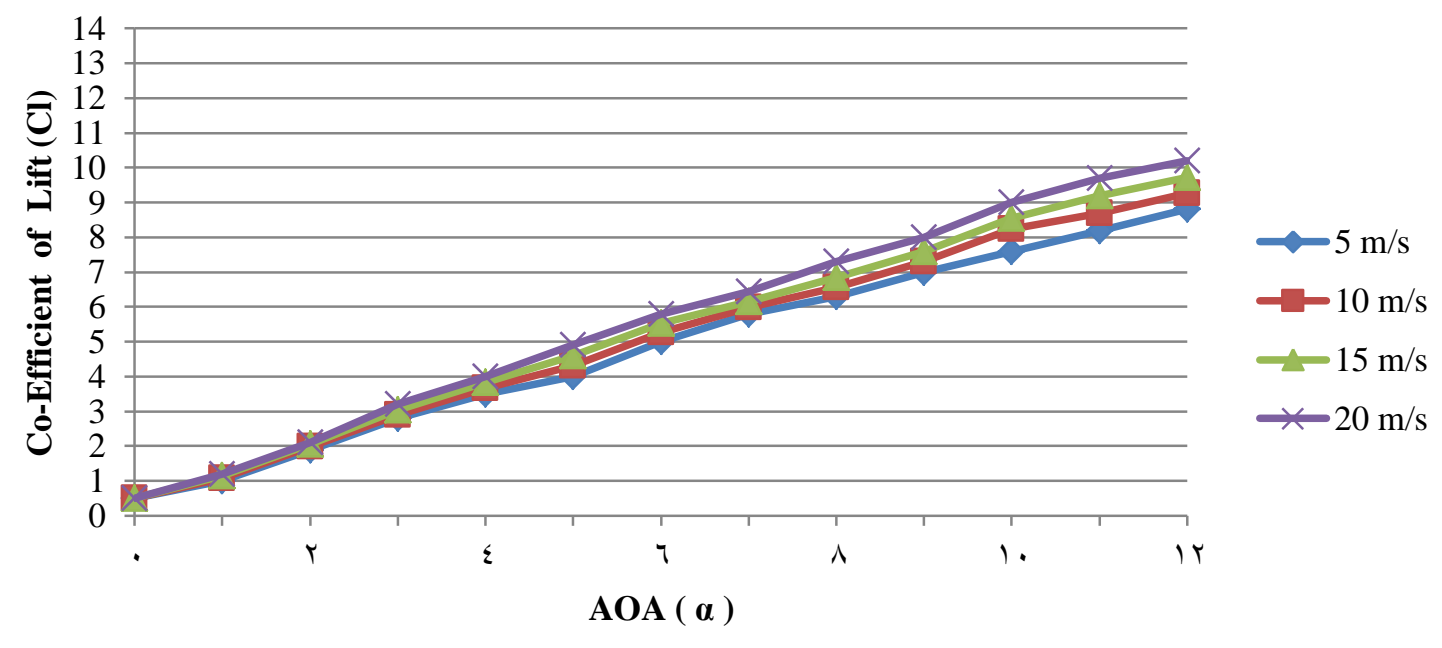

Figure 7: Increase in lift for various AOA

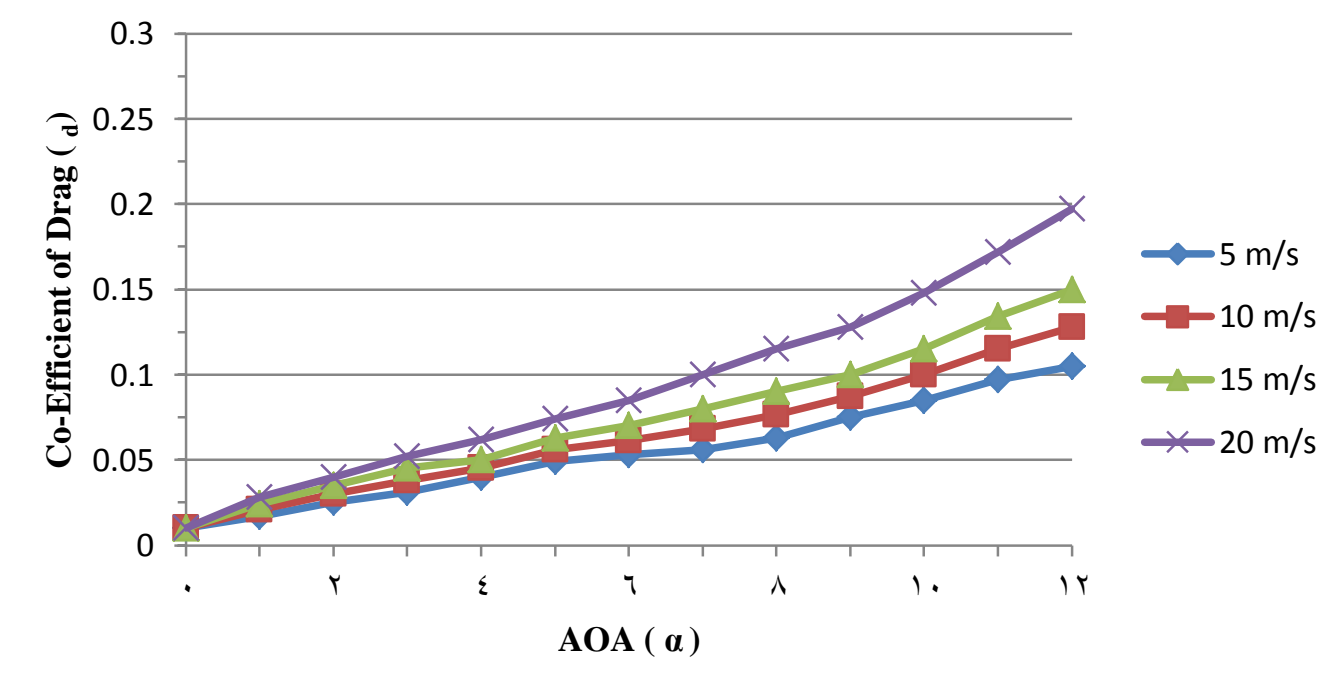

Figure 7: Increase in drag for various AOA

\section{At the velocity $5 \mathrm{~m} / \mathrm{s}$}




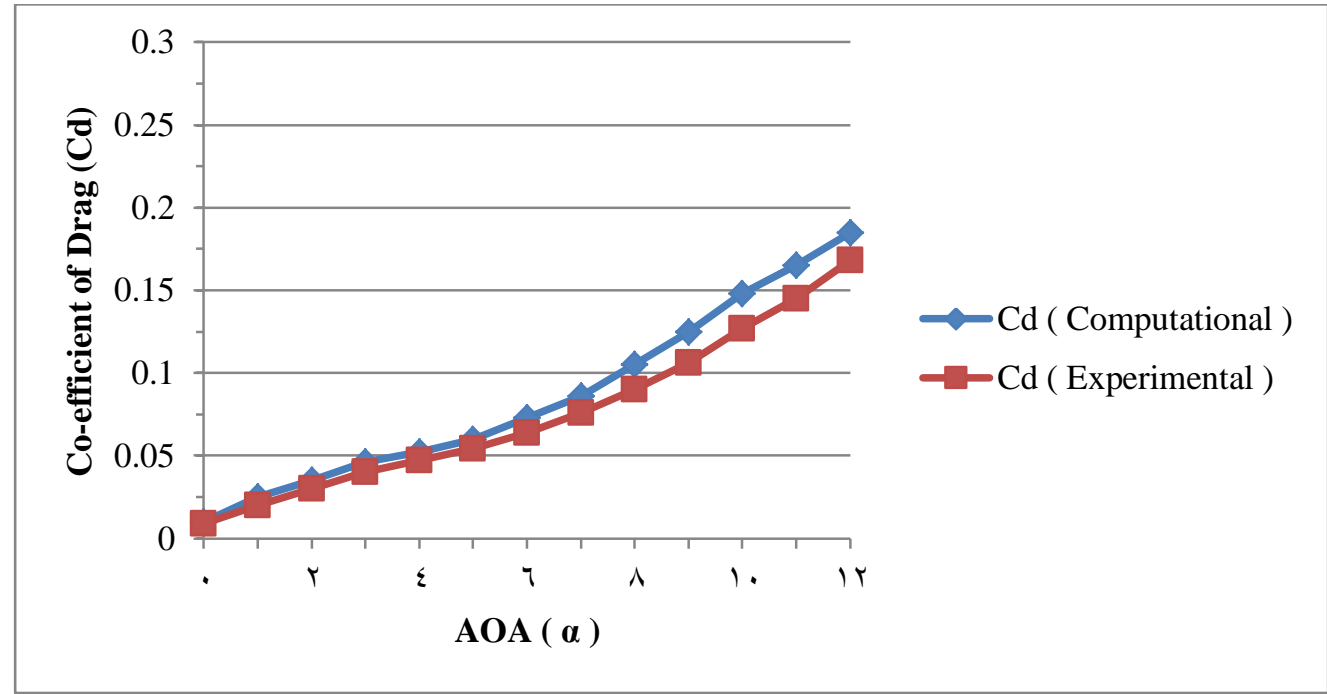

Figure 8: Coefficient of drag $\left(\mathrm{C}_{\mathrm{d}}\right)$ Versus AOA

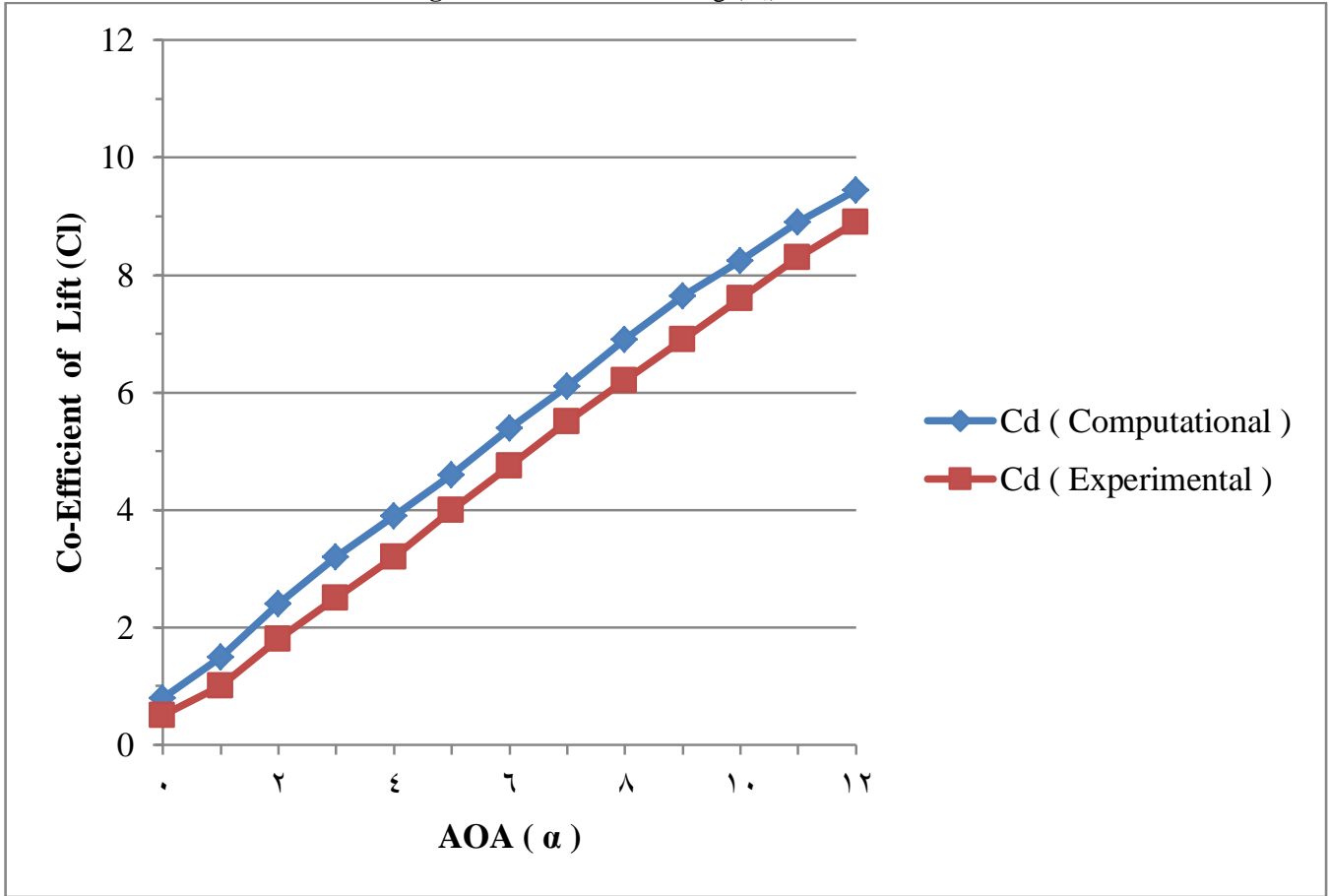

Figure 9: Coefficient of lift $\left(\mathrm{C}_{\mathrm{l}}\right)$ Versus AOA 


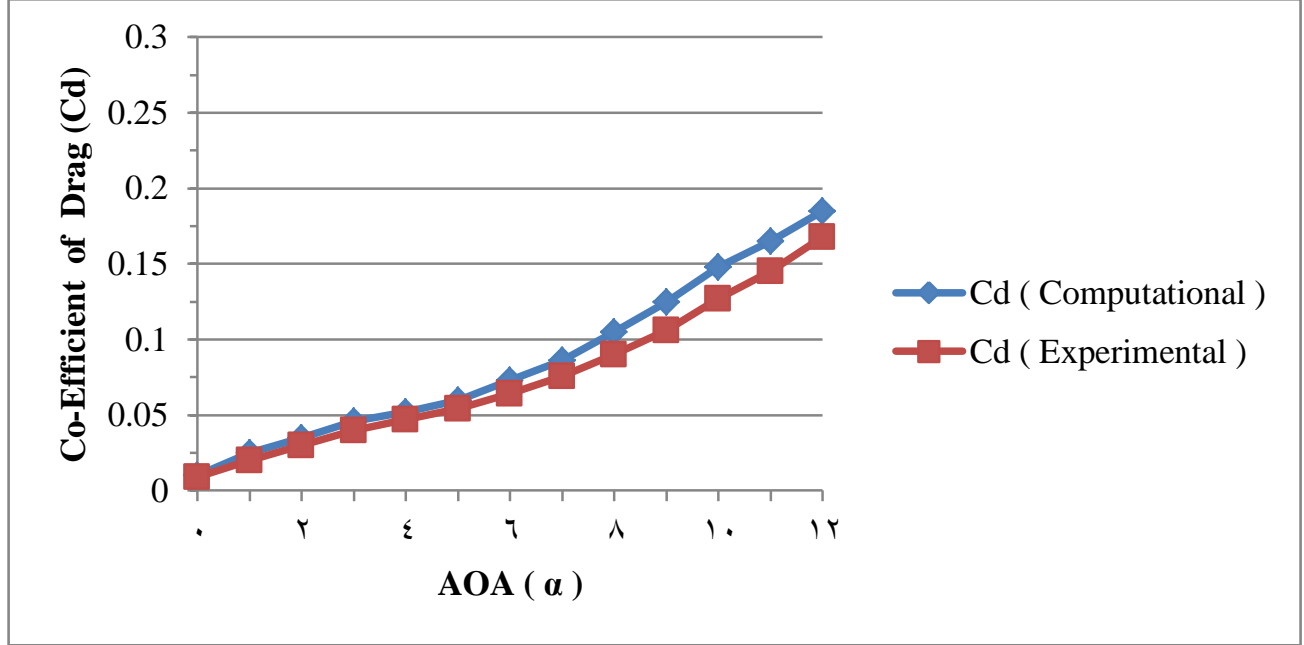

Figure 10: Coefficient of drag $\left(C_{d}\right)$ Versus AOA

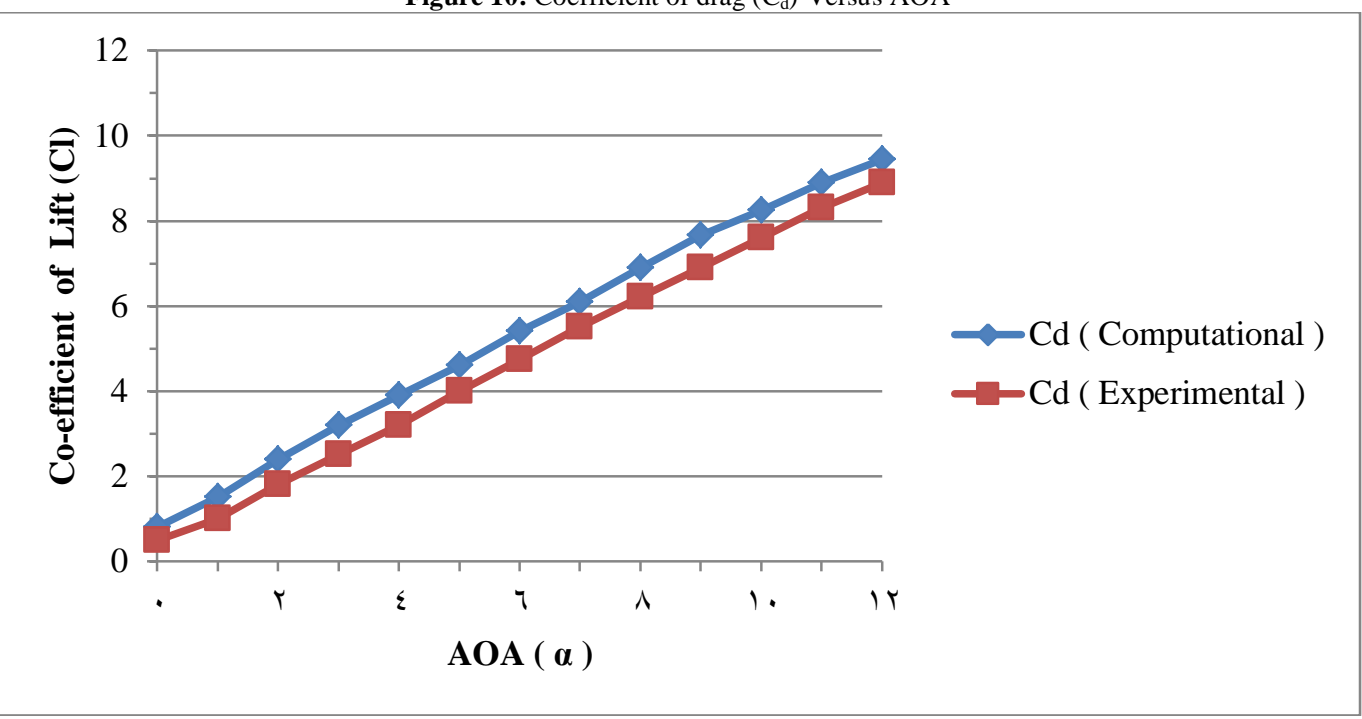

Figure 11: Coefficient of lift $\left(\mathrm{C}_{\mathrm{l}}\right)$ Versus AOA

\section{At the velocity $15 \mathrm{~m} / \mathrm{s}$}

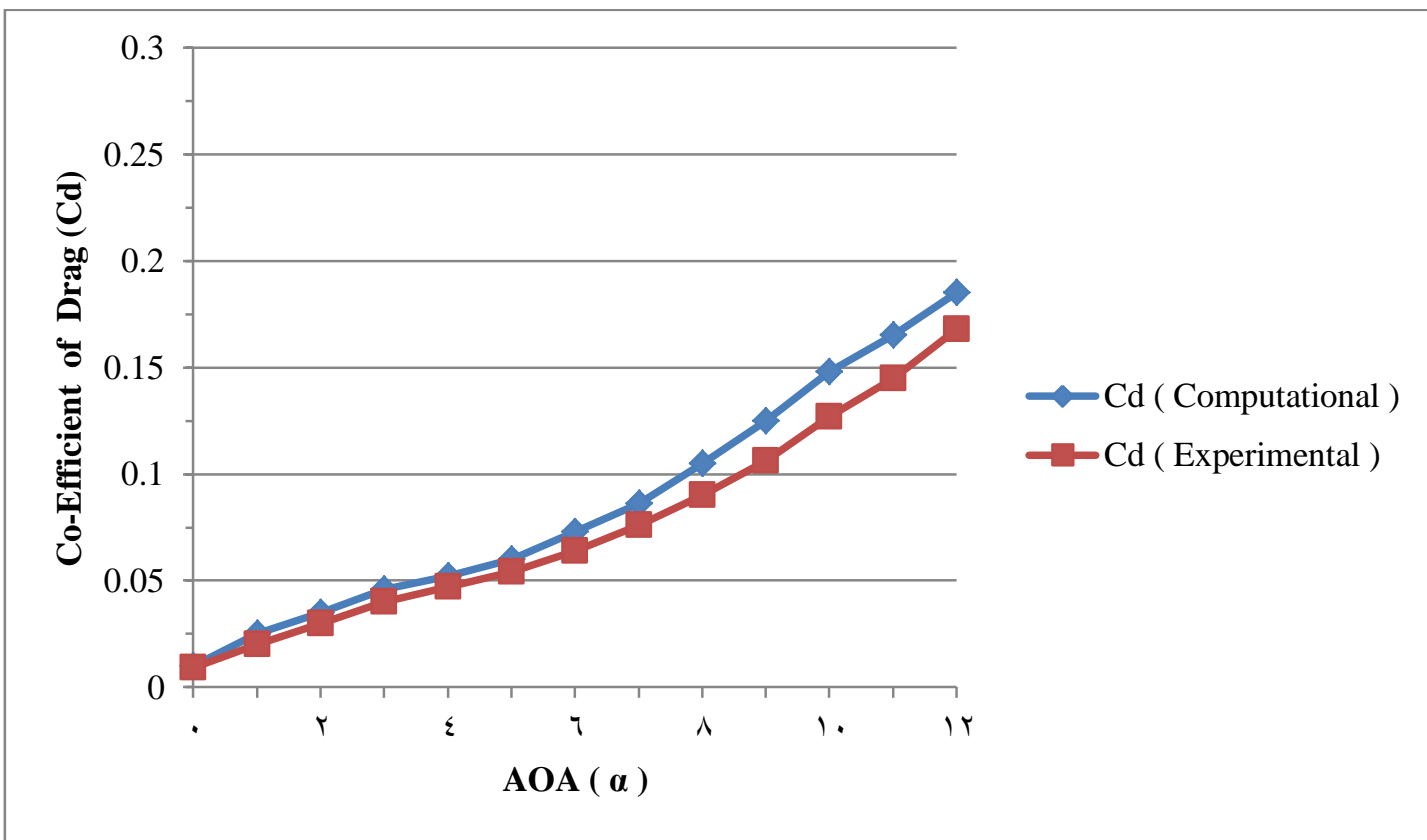

Figure 12: Coefficient of drag $\left(C_{d}\right)$ Versus AOA 


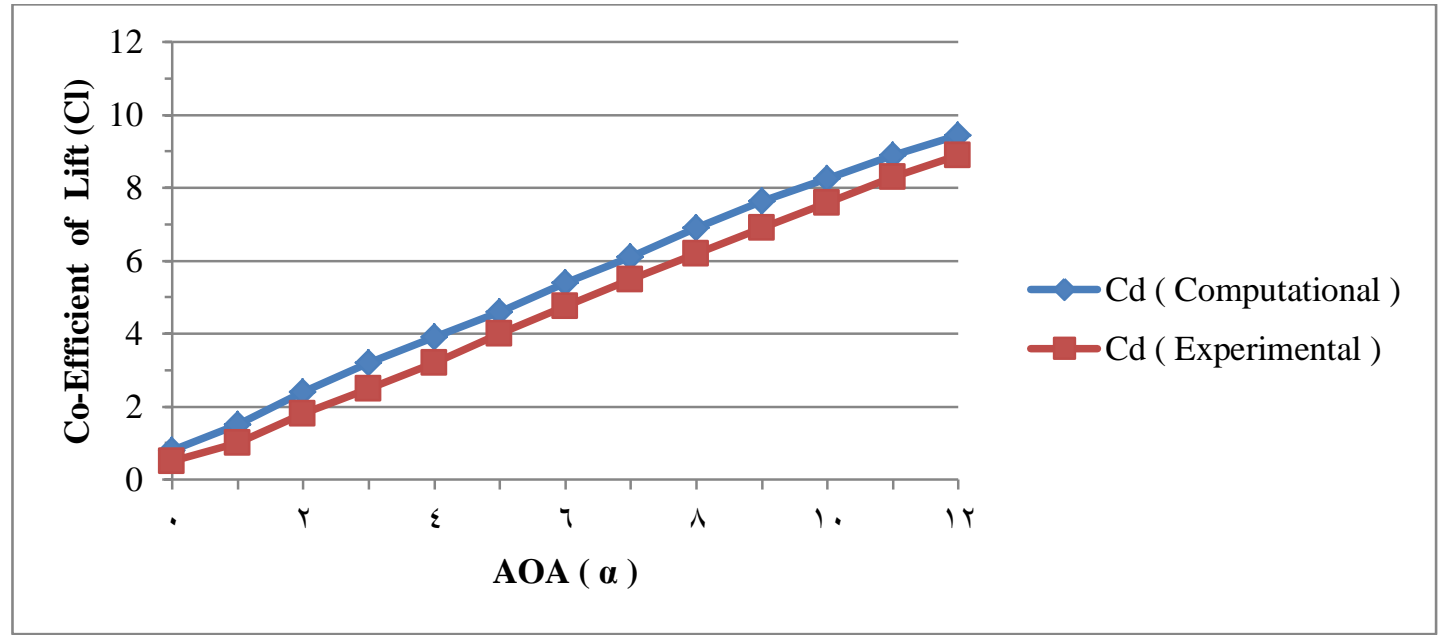

Figure 13: Coefficient of lift $\left(\mathrm{C}_{\mathrm{l}}\right)$ Versus AOA

From the contours, we see that there is a region of high pressure at pressure at angles of attack $0^{\circ}$ to $12^{\circ}$ with spalart allmaras model. the leading edge (stagnation point) and region of low pressure on the upper surface of aerofoil. From Bernoulli equation, we know that whenever there is high velocity, we have low pressure and vice versa. Figure 1 to 6 shows the simulation outcomes of static The pressure on the lower surface of the aerofoil was greater than that of the incoming flow stream and as a result it effectively "pushed" the aerofoil upward, normal to the incoming flow stream.

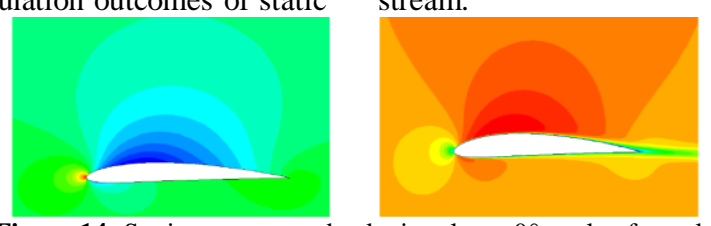

Figure 14: Static pressure and velocity plot at $0^{\circ}$ angle of attack

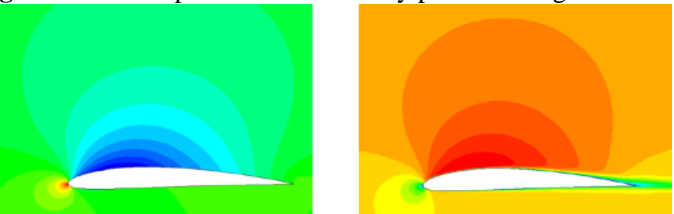

Figure 15: Static pressure and velocity plot at $2^{\circ}$ angle of attack

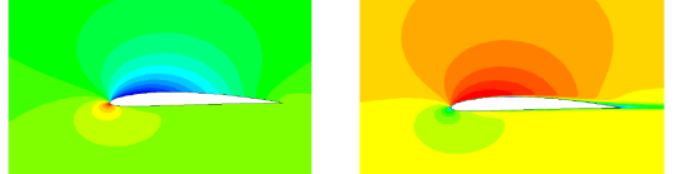

Figure 16: Static pressure and velocity plot at $4^{\circ}$ angle of attack

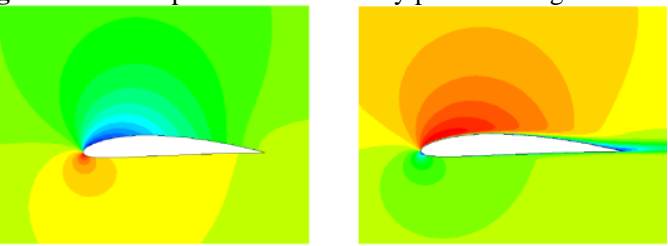

Figure 17: Static pressure and velocity plot at $6^{\circ}$ angle of attack

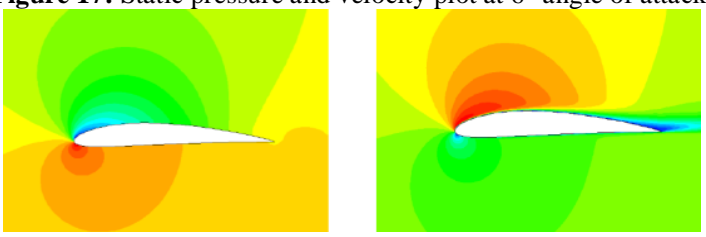

Figure 18: Static pressure and velocity plot at $8^{\circ}$ angle of attack

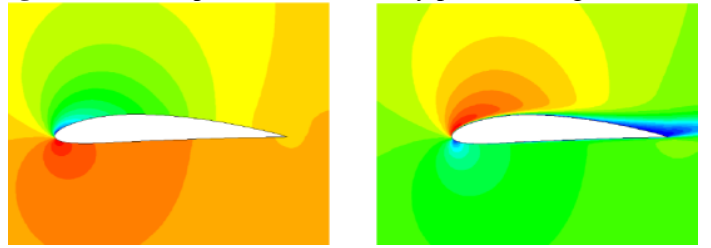

Figure 19: Static pressure and velocity plot at $10^{\circ}$ angle of attack 


\section{Conclusion}

The bends of the lift and the drag coefficient are appeared for different approaches, registered with spalart-allmaras demonstrate and contrasted and information of NACA 4412 for $\mathrm{Re}=1 \times 105$. The coefficient of Lift and drag is ascertained for this NACA 4412 arrangement for the approach $0^{\circ}$ to $12^{\circ}$. The coefficient of Lift/Drag proportion increments with increment in Angle of assault up to $8^{\circ}$. After $8^{\circ}$, Lift/Drag proportion diminishes with increment in Angle of assault. $0^{\circ}$ to $12^{\circ}$. The coefficient of Lift/Drag ratio increases with increase in Angle of attack up to $8^{\circ}$. After $8^{\circ}$, Lift/Drag ratio decreases with increase in Angle of attack. Computational fluid dynamics is used to analysis the flow behaviour of the aerofoil in 2D. The coefficient of Lift and drag is calculated for this NACA 4412 series for the angle of attack $0^{\circ}$ to $12^{\circ}$. The coefficient of Lift/Drag ratio increases with increase in Angle of attack up to $6^{\circ}$. After $6^{\circ}, \mathrm{Lift} /$ Drag ratio decreases with increase in angle of attack.

\section{References}

[1] Jadallaha AA, Mahmooda DY \& Abdulqaderb ZA, "Optimal Performance of Horizontal Axis Wind Turbine for Low Wind Speed Regime", International Journal of Multidisciplinary and Current Research, (2014).

[2] Carrigan TJ, Dennis BH, Han ZX \& Wang BP, “Aerodynamic Shape Optimization of a Vertical-Axis Wind Turbine Using Differential Evolution", International Scholarly Research Network, ISRN Renewable Energy, (2011).

[3] Ali A, Golde S, Alam F \& Moria H, "Experimental and computational study of a micro vertical axis wind turbine", Procedia engineering, Vol.49, (2012), pp.254-262.

[4] Chong WT, Poh SC, Fazlizan A \& Pan KC, "Vertical Axis Wind Turbine with Omni-Directional-Guide-Vane for Urban High Rise Application", Journal of Central South University of Technology, Vol.19, No.3,(2012), pp.727-732.

[5] Wang H, Wang J, Yao J, Yuan W \& Cao L, "Analysis on the aerodynamic performance of vertical axis wind turbine subjected to the change of wind velocity. Procedia Engineering, Vol.31, (2012), pp.213-219.

[6] Yao J, Wang J, Yuan W, Wang H \& Cao L, "Analysis on the influence of Turbulence model changes to aerodynamic performance of vertical axis wind turbine", Procedia Engineering, Vol.31, (2012), pp.274-281.

[7] Hwang IS, Min SY, Jeong IO, Lee YH \& Kim SJ, "Efficiency improvement of a new vertical axis wind turbine by individual active control of blade motion, Smart structures and materials", Conference, ETATS-UNIS, Vol.6173, (2006).

[8] Najar FA \& Harmain GA, "Blade Design and Performance Analysis of Wind Turbine", International Conference on Global Scenario in Environment and Energy, (2013).

[9] Chris K, Austin F, Paul Z \& Wael M, "A CFD Study of Wind Turbin e Aerodynamics", Proceedings of the ASEE North Central Sectio $n$ Conference, (2012).

[10] DeCoste J, McKay D, Robinson B, Whitehead S, Wright S, Koksal M \& Hughes L, "Vertical Axis Wind Turbine", Department of Mechanical Engineering, (2015).

[11] Srinivas G, Mahesha GT, Chethan KN and Arjun N, "Analysis of Wind Turbine Blade", International Journal of Current Engineering and Technology, (2014).

[12] Shah DU, Schubel PJ \& Clifford MJ, "Can Flax Replace E-Glass in Structural Composites? A Small Wind Turbine Blade Case Study", Composites: Part B, Vol.52, (2013), pp.172-181.

[13] Silva CT \& Donadon MV, "Unsteady blade element-momentum method including returning wake effects", Journal of Aerospace Technology and Management, Vol.5, No.1, (2013), pp.27-42.

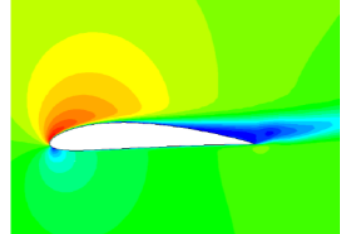

[14] Guo Y, Keller J, Moan T \& Xing Y, "Model Fidelity Study of Dynamic Transient Loads in a Wind Turbine Gearbox", Conference Paper NREL/CP-5000-58414, (2013).

[15] Ahmad A, Elahi, Z \& Babar M, "CAD-CAE integration of horizontal axis wind turbine", Advances in Energy and Power, Vol.1, No.2,(2013), pp.56-61.

[16] Hsiao FB, Bai CJ \& Chong WT, "The performance test of three different horizontal axis wind turbine (HAWT) blade shapes using experimental and numerical methods", Energies, Vol.6, No.6, (2013), pp.2784-2803.

[17] Rachman A, Muhtar LA, Levi S \& Salea N, "An experiment on horizontal and vertical wind turbines with incorporation of rounded shroud device using wind simulation in a vehicle", International Journal of Innovation and Applied Studies, (2013), pp.365-374.

[18] Santhana Kumar P, Abraham A, Joseph Bensingh R \& Ilangovan S, "Computational and Experimental Analysis of a Counter-Rotating wind Turbine System", Journal of science and Industry Research Vol.72, (2013), pp.300-306.

[19] Pathike P, Katpradit T, Terdtoon P \& Sakulchangsatjatai P, "A new design of blade for small horizontal-axis wind turbine with low wind speed operation", Energy Research Journal, Vol.4, (2013), pp.1-7.

[20] Kishore RA, Coudron T \& Priya S, "Small-scale wind energy portable turbine (SWEPT)", Journal of Wind Engineering and Industrial Aerodynamics, Vol.116, (2013), pp.21-31.

[21] Mo JO, Choudhry A, Arjomandi M \& Lee YH, "Large eddy simulation of the wind turbine wake characteristics in the numerical wind tunnel model", Journal of Wind Engineering and Industrial Aerodynamics, Vol.112, (2013), pp.11-24.

[22] Almukhtar AH, "Effect of Drag on the Performance for an Efficien Wind Turbine Blade Design", Engineering, Vol.49, (2012), pp.404415 .

[23] Kosasih B \& Tondelli A, "Experimental Study of Shrouded MicroWind Turbine", Proceedia Engineering, Vol.49, (2012), pp.92-98.

[24] Tartibu LK, Kilfoil M \& Van Der Merwe AJ, "Vibration Analysis of a Variable Length Blade Wind Turbine", International Journal of Advance in Engineering \& Technology, Vol.4, No.1, (2012), pp 630-639.

[25] Mahawadiwar HV, Dhopte VD, Thakare PS \& Askhedkar RD, "CFD Analysis of Wind Turbine Blade", International Journal of Engineering Research and Applications, (2012), pp.3188-3194.

[26] Rajendran C, Madhu G, Tide PS \& Kanthavel K, "Aerodynamic Performance Analysis of HAWT Using CFD Technique", European Journal of Scientific Research, Vol.65, No.1, (2011), pp 28-37.

[27] Amano RS \& Malloy RJ, "CFD Analysis on Aerodynamic Design Optimization of Wind Turbine Rotor Blades", World Academy of Science and Technology, Vol.60, (2009).

[28] Akhpanov, S. Sabitov, R. Shaykhadenov (2018). Criminal pre-trial proceedings in the Republic of Kazakhstan: Trend of the institutional transformations. Opción, Año 33. 107-125. 